\title{
SISTEMA NORMATIVO DE AGROTÓXICOS NA CONTEMPORANEIDADE
}

\author{
Cleber Adriano Rodrigues Folgado ${ }^{1}$
}

\begin{abstract}
RESUMO
Desde 2008 o Brasil é o maior consumidor de agrotóxicos do mundo, entretanto o uso massivo de tais produtos na agricultura brasileira vem desde a década de 1960. A normatização do uso de tais substâncias vigorou em âmbito federal sem norma específica até a edição da Lei 7.802, de 11 de julho de 1989, mais conhecida como "Lei dos Agrotóxicos". Já nos seus primórdios, a Lei provocou fortes debates e enfrentamentos, no entanto, recentemente, foi protocolado na Câmara dos Deputados o Projeto de Lei $3200 / 15$, que altera completamente a estrutura do sistema normativo de agrotóxicos e propõe a revogação da Lei 7.802/89. As alterações propostas representam o desmonte de várias conquistas resultantes de lutas históricas do povo brasileiro positivadas em nosso sistema jurídico. Este artigo pretende expor acerca deste processo.
\end{abstract}

Palavras-chave: Revolução Verde. Agronegócio. Lei de Agrotóxicos. Projeto de Lei.

\section{INTRODUÇÃO}

Sabe-se que a agricultura é praticada pelo ser humano há mais de 10 mil anos, e obviamente que ao longo de todo este período, muitas inovações tecnológicas foram desenvolvidas a fim de melhorar as condições de trabalho, de aumentar a produtividade, etc. É nesse sentido que os agrotóxicos são apresentados para a agricultura mundial. Entretanto, tais substâncias surgem no mundo com objetivos bélicos e não voltados para resolver os problemas da agricultura.

Com o fim da Segunda Guerra Mundial em 1945, o complexo bélico encontrava-se com dois grandes problemas no que se refere às substâncias tóxicas, sendo o primeiro deles o fato de ainda restar enormes quantidades de armas químicas estocadas, e o segundo, o fato de terem um enorme complexo industrial bélico que corria o risco de ficar obsoleto. Para resolver este problema, buscou-se a adaptação destes "restos de guerra" para que pudessem ser utilizados na agricultura. É assim que surge a famosa Revolução Verde.

Como destaca PEREIRA:

\footnotetext{
${ }^{1}$ Camponês. Graduando em Direito (Turma Elizabeth Teixeira - PRONERA), pela Universidade Estadual de Feira de Santana.
} 
O processo de modernização da agricultura ao longo do século XX levou a grandes transformações e a uma ruptura no modo de conceber a agricultura. Podemos considerar a Revolução Verde como um novo paradigma, quando comparado a chamada Primeira Revolução Agrícola, que diz respeito à intensificação do uso da terra, porém referenciada nos recursos e ciclos ecológicos endógenos. ${ }^{2}$

Este novo paradigma de produção trazia consigo a promessa de que com a adoção do pacote, os países poderiam produzir em maior quantidade e com maior qualidade, de modo que a erradicação da fome no mundo era algo que seria facilmente resolvido. Outra promessa importante era a diminuição da penosidade ${ }^{3}$ do trabalho no campo. Assim a Revolução Verde se popularizou no mundo todo, com a ajuda de recursos nacionais e internacionais, os países puderam ir adotando o pacote.

O contraditório foi que passaram-se mais de cinquenta anos de adoção ao pacote da Revolução Verde, e a fome ainda é um grave problema mundial. No Brasil, de acordo com o PNAD/IBGE 4 , 22,3 \% da população, ou seja, cerca de 52 milhões de pessoas, encontra-se em situação de insegurança alimentar. Quanto à fome, que é a expressão mais grave da insegurança alimentar e nutricional, o percentual de brasileiros nesta condição é de 3,2\%, ou seja, cerca de 7,2 milhões de pessoas.

Como podemos perceber a Revolução Verde não resolveu o problema da fome, e quanto à penosidade do trabalho, podemos dizer que a resolveu parcialmente, pois com a adoção de maquinários, em muitos casos o resultado foi a expulsão de pessoas do campo, de modo que as máquinas passaram a ocupar o lugar onde antes haviam camponeses. O êxodo rural tornou-se um processo intrínseco ao pacote da Revolução Verde. Além disso, outros problemas passaram a ser recorrentes para os trabalhadores do campo, de modo que a penosidade do trabalho não acabou, e em muitos casos, ela simplesmente se metamorfoseou, transformando-se em outras duras penas, como por exemplo, em contaminações por agrotóxicos.

\footnotetext{
${ }^{2}$ PEREIRA, Mônica Cox de Britto. Revolução Verde. In: CALDART, Roseli Salete (Org.); PEREIRA, Isabel Brasil; ALENTEJANO, Paulo et al. Dicionário de Educação do Campo. Rio de Janeiro-São Paulo: Escola Politécnica de Saúde Joaquim Venâncio/Expressão Popular, 2012, p. 685-686.

${ }^{3}$ Refere-se a atividade laboral realizada de forma sofrida, com dificuldades.

${ }^{4}$ Trata-se da Pesquisa Nacional por Amostra de Domicílios - PNAD, realizada pelo Instituto Brasileiro de Geografia e Estatísticas - IBGE em 2013.
} 
O pacote da Revolução Verde trazia consigo sementes híbridas, agrotóxicos, fertilizantes, novas técnicas de semeadura, de adubação, mecanização para plantio, irrigação e colheita, padronização dos campos, dentre diversas outras alterações na forma de produção agrícola até então massivamente praticada. A Revolução Verde significa, portanto, o processo de industrialização da agricultura. Ao tratar especificamente dos agrotóxicos nesse processo, Rachel Carson ${ }^{5}$ irá atribuí-los “a súbita ascensão e ao assombroso crescimento de uma indústria de produção de substâncias químicas artificiais ou sintéticas com propriedades inseticidas" ${ }^{\text {. }}$

\section{AGRONEGÓCIO: A CONTINUIDADE DA REVOLUÇÃO VERDE}

O modelo de produção atualmente hegemônico no país é o agronegócio, que por sua vez representa a continuidade da Revolução Verde com um grau mais elevado de modernização e relações mais complexas. Viabiliza-se através da permanente aliança entre o capital financeiro internacional que tem como representante direto os grandes bancos; as empresas transnacionais e o latifúndio. Tal modelo recebe ainda apoio incondicional dos meios de comunicação hegemônicos que invisibilizam os problemas gerados pelo modelo, e superdimensionam as suas supostas vantagens. Além, disso, o Estado tem sido o principal financiador do agronegócio, pois reiteradamente têm proporcionado condições econômicas através de créditos, ou renegociação e perdão de dívidas para a continuidade do modelo.

O agronegócio têm, dentre outros, cinco principais pilares de sustentação de sua lógica produtiva. Tratam-se da produção de monocultivos, do uso de maquinário de grande porte, do latifúndio, da produção voltada para exportação e, do uso indiscriminado de agrotóxicos e sementes transgênicas. Vejamos cada um deles:

\footnotetext{
${ }^{5}$ Rachel Carson publicou a obra Silent spring (Primavera Silenciosa) em setembro de 1962 na forma de livro, antes precedida pela publicação em junho do mesmo ano na forma de série pela revista New Yorker. Esta foi a primeira publicação a questionar a indústria química tóxica e a forma como a humanidade vinha fazendo uso destes produtos. Tornou-se um clássico não apenas por ser pioneira, mas principalmente pela clareza e profundidade com que abordou a questão, trazendo a público a denúncia dos males causados identificados até então - pelos pesticidas. Ao tratar do que chamamos de agrotóxicos a autora dizia "Eles não deviam ser chamados de 'inseticidas', e sim de 'biocidas", e ainda acrescentava um importante questionamento que nos cabe perfeitamente nos dias de hoje "Será que alguém acredita que é possível lançar tal bombardeio de venenos na superfície da Terra sem torná-la imprópria para toda a vida?" (CARSON, Rachel. Primavera Silenciosa. Tradução de Claudia Sant'Anna Martins. São Paulo: Gaia, 2010, p.24).

${ }^{6}$ CARSON, Rachel. Primavera Silenciosa. Tradução de Claudia Sant'Anna Martins. São Paulo: Gaia, 2010, p.29.
} 
a) A produção em monocultivos ${ }^{7}$, refere-se ao plantio de apenas um tipo de cultura. Tal forma de produção rompe com o equilíbrio ambiental, onde as diferentes plantas conseguem manter a existência de diferentes tipos de animais e insetos que por sua vez exercem o controle natural de "pragas"; dessa forma a produção com base em monocultivos proporciona o surgimento e a proliferação de determinadas populações de insetos e plantas que por sua vez vão se tornar nocivos à produção.

b) O uso de maquinário pesado, de grande porte, tornou-se uma necessidade, visto que a produção é feita em larga escala. Porém, tais máquinas também afetam negativamente o ambiente já que terminam por exercer um processo compactação e consequente erosão do solo, o que por sua vez, faz com que a cada ano haja uma necessidade maior de aplicação de fertilizantes químicos que alimentam apenas a planta e não garantem a recuperação da fertilidade da terra. A compactação do solo associada a outros problemas vai matando a terra, que antes viva, passa a ser apenas um suporte para a realização do ato produtivo dependente de insumos. Este processo apenas contribui para uma aceleração da degradação ambiental.

c) O latifúndio, antes tido como atrasado, com a adoção deste modelo passa a expressar-se através das grandes propriedades de terras que agora têm espaço na produção. Grandes extensões de terra com monocultivos passam a ocupar o território nacional. Assim o latifúndio, torna-se condição sine qua non de existência do agronegócio, até mesmo porque para que se utilize maquinário de grande porte são necessárias grandes extensões de terra. Esta necessidade tem resultado em um processo de concentração e centralização da terra em poucas mãos, e em muitos casos sob controle de estrangeiros que adquiriram propriedades no país, em especial após a crise de 2008.

d) A produção voltada para a exportação, tornou-se a grande aposta do agronegócio, de modo que a lógica que impera sobre o que será ou não produzido é determinado em função da demanda internacional. Supostamente este seria o eixo forte do agronegócio, visto que as exportações garantem a entrada de dívidas e contribuí portanto para manter o equilíbrio da balança comercial frente ao superávit primário. Todavia, alertamos para o fato de que nesta matemática, não são calculados os custos sociais e ambientais advindos da lógica produtivista do agronegócio, de modo que existe

\footnotetext{
${ }^{7}$ Erroneamente costuma-se utilizar o termo monocultura, porém é importante destacar que nenhuma cultura é mono por natureza. As plantas em seu ambiente natural nascem, crescem e se desenvolvem em convívio com outras plantas. O que existe é o cultivo por parte do homem de determinadas plantas, impondo-lhes a pretensão de unicidade no espaço produtivo. Assim, o correto do ponto de vista terminológico é falar-se em monocultivos e não em monocultura.
} 
uma tergiversação dos números, afinal, os gastos sociais e o custo ambiental da adoção desta lógica, não calcula-se apenas a curto prazo, mas a médio e longo prazo. Importante ainda lembrar que é justamente a aceitação de garantir uma produção voltada para atender com os interesses internacionais de exportação, que transformou o Brasil em um grande produtor - e exportador - de commodities ${ }^{8}$, paradoxalmente opondo-se assim a seu mais importante potencial: ser um dos maiores produtores de alimentos do mundo.

e) Por último, e não menos importante, está o uso indiscriminado de agrotóxicos, que se tornou uma necessidade inevitável, afinal, com as imensas plantações de monocultivos proliferam determinadas plantas e insetos indesejados no espaço produtivo, denominados de "pragas" pelos adeptos do agronegócio. Na perspectiva destes, os agrotóxicos são a única forma de garantir a eliminação destas ameaças representadas por plantas, insetos, fungos e outros organismos indesejáveis na lavoura. As promessas feitas com as sementes transgênicas só aumentaram esse uso indiscriminado, pois em sua grande maioria as plantas geneticamente modificadas tiveram alterações para tornarem-se resistentes a algum tipo de agrotóxico. Assim, com o uso das sementes transgênicas no país o uso de agrotóxicos aumentou consideravelmente, ao ponto de que após a introdução dessas sementes no país, nós nos tornássemos desde 2008 o maior consumidor de agrotóxicos do mundo, e segundo maior produtor mundial de organismos geneticamente modificados - OGMs. ${ }^{10}$

\section{SISTEMA NORMATIVO DE AGROTÓXICOS}

\footnotetext{
${ }^{8} \mathrm{~N}$ do A. "Commodities são produtos de origem mineral ou vegetal, geralmente em estado bruto ou com pouco beneficiamento, produzido em massa e com características homogêneas, independentemente de sua origem. Seu preço, normalmente, é definido pela demanda, e não pelo produtor. Alguns exemplos de commodities são soja, café, açúcar, ferro e alumínio". (RIGOTTO, Raquel Maria; ROSA, Islene Ferreira. Agrotóxicos. In: CALDART, Roseli Salete (Org.); PEREIRA, Isabel Brasil; ALENTEJANO, Paulo et al. Dicionário de Educação do Campo. Rio de Janeiro-São Paulo: Escola Politécnica de Saúde Joaquim Venâncio/Expressão Popular, 2012, p.91).

${ }^{9} \mathrm{Na}$ perspectiva agroecológica não se utiliza o termo praga, visto que tratam-se tão somente de animais e plantas indesejados no espaço de produção e que na prática se constituem em indicadores de determinada deficiência do solo ou das plantas. Assim, ao invés de pragas, aos olhos do camponês com domínio das técnicas agroecológicas, tornam-se importantes agentes indicadores das deficiências que devem ser corrigidas no sistema de produção.

10 “O Brasil tem, hoje, a segunda maior área cultivada com plantas transgênicas do planeta e é o único país do mundo a ter liberado o uso comercial de mosquitos transgênicos para combate à dengue, mesmo sem o posicionamento e autorização da Anvisa sobre a produção, venda e uso desses mosquitos geneticamente modificados" (CARNEIRO, Fernando Ferreira (Org.); AUGUSTO, Lia Giraldo da Silva; RIGOTTO, Raquel Maria et al. Dossiê ABRASCO: um alerta sobre os impactos dos agrotóxicos na saúde. Rio de Janeiro-São Paulo: EPSJV/Expressão Popular, 2015, p.423).
} 
Desde 2008 o Brasil é o país que mais consome agrotóxicos no mundo. ${ }^{11}$ Destarte, não há dúvidas de que a Revolução Verde contribuiu significativamente para este processo, que é mantido atualmente pelo agronegócio, principal responsável pelo uso de agrotóxicos na atualidade.

Os agrotóxicos - elementos do pacote da Revolução Verde - são incorporados massivamente no país na década de 1960, tendo destaque especial a criação “[...] em 1965 do Sistema Nacional de Crédito Rural, que vinculava a obtenção do crédito agrícola à obrigatoriedade da compra de insumos químicos pelos agricultores" ${ }^{12}$. Este mecanismo massificou rapidamente a prática do uso de agrotóxicos, aumentado inclusive a demanda de consumo em relação a estes produtos. Desse modo, objetivando suprir a dependência externa, é criado em 1975, no âmbito do II Plano Nacional de Desenvolvimento, o Programa Nacional de Defensivos Agrícolas que “[...] proporcionou recursos financeiros para a criação de empresas nacionais e a instalação no país de subsidiárias de empresas transnacionais de insumos agrícolas" ${ }^{13}$, dentre elas, as empresas de produção de agrotóxicos, como destaca Fideles:

No Brasil, o Plano Nacional de Desenvolvimento Agrícola (PNDA), lançado em 1975, incentivava e exigia o uso de agrotóxicos, oferecendo investimentos para financiar esses "insumos" e também para ampliar a indústria de síntese e formulação no país, que passaria de 14 fábricas em 1974 para $73 \mathrm{em} 1985 .{ }^{14}$

Nesse período, não havia legislação específica sobre os agrotóxicos no país, de modo que a produção, comercialização e uso, era normatizada por institutos esparsos, tendo como base principal o Decreto 24.114 de, 12 de abril de $1934^{15}$, que tratava sobre a Defesa Sanitária Vegetal. Destarte, menciona Ferrari “Até 1970, outras leis e decretos seriam incorporados à legislação sanitária, mas sem tratar diretamente de agrotóxicos"16.

11 Cf. Ibid., p. 49

12 LONDRES, Flávia. Agrotóxicos no Brasil: um guia em defesa da vida. Rio de Janeiro: AS-PTA Assessoria e Serviços a Projetos em Agricultura Alternativa, 2011, p.18.

${ }^{13}$ Ibid., p. 18

${ }^{14}$ FIDELES, 2006, apud RIGOTTO, Raquel Maria; ROSA, Islene Ferreira. Agrotóxicos. In: CALDART, Roseli Salete (Org.); PEREIRA, Isabel Brasil; ALENTEJANO, Paulo et al. Dicionário de Educação do Campo. Rio de Janeiro-São Paulo: Escola Politécnica de Saúde Joaquim Venâncio/Expressão Popular, 2012 p.86-87

15 "Na verdade, a legislação nacional de agrotóxicos foi oriunda da revolução de 1930, havendo sido publicada como decreto em 1934 e depois confirmada com o valor de Lei”. (PINHEIRO, Sebastião; NASR, Nasser Youssef; LUZ, Dioclécio. A Agricultura Ecológica e a Máfia dos Agrotóxicos no Brasil. Porto Alegre: Edição dos Autores, 1993, p.84).

${ }^{16}$ N. do A. "Decreto-Lei 986, de 21 de outubro de 1969, trata de normas básicas para alimentos; Lei 5.760, de 03 de dezembro de 1971, dispõe sobre inspeção sanitária e industrial dos produtos de origem animal; Lei 6.138, de 08 de novembro de 1974, diz respeito à fiscalização do comércio de fertilizantes, corretivos e inoculantes destinados à agricultura; Lei 6.360, de 23 de setembro de 1976, dispõe sobre a vigilância 
Vários dispositivos do Decreto 24.114/34 normatizam a questão dos agrotóxicos - que não eram tratados com esta nomenclatura - porém os dispositivos principais encontram-se no capítulo VI que vai do art. 52 ao art. 75 e trata da fiscalização de inseticidas e fungicidas com aplicação na lavoura. Dentre as várias exigências destacam-se as contidas no art. 53 para obtenção de registro e licença do produto, tendo extrema relevância a imposição da validade do registro por apenas 5 anos, de modo que os interessados em manter o produto no mercado deviam renová-lo obrigatoriamente, decorrido este prazo.

Em 1970, no dia 27 de agosto, foi publicado no Diário Oficial da União o Decreto $n^{\circ} 67.112$, que por sua vez aprovou normas técnicas especiais para controle da fabricação e venda de produtos saneantes e congêneres. Tais normas tinham por objeto o controle da fabricação, manipulação, fracionamento, venda e demais operações concernentes aos produtos saneantes. Enquadravam-se dentro da área de abrangência da norma todo e qualquer produto, seja qual for a sua finalidade, que encerrar em sua composição, substância destinada à prevenção, controle e combate a agente-nocivos ao homem, aos vegetais e animais domésticos.

Dentro da conceituação adotada pelo Decreto (67.112/70), os agrotóxicos são definidos como Produto Saneante Fitossanitário (art. $2^{\circ}$, I, b), sendo caracterizado pela norma como produto saneante toda substância ou preparação destinada à higienização, desinfecção ou desinfestação, inclusive ao tratamento da água e do solo, assim compreendidos: a) domissanitário - o de aplicação nos domicílios, ambientes coletivos, públicos e lugares de uso comum, e no tratamento da água; b) fitossanitário - o de aplicação em vegetais e seus produtos, e no tratamento do solo; c) zoossanitário - o de aplicação em animais, especialmente na pecuária.

Como já mencionado, vários decretos e outros diplomas normativos vão sendo criados a fim de suprir os vazios existentes em relação a questão dos agrotóxicos. No entanto, independentemente da existência ou não de norma - ou talvez até mesmo em virtude de sua inexistência específica - o uso de agrotóxicos só aumentava e isso chamou a atenção de grupos ligados às questões ambientais.

sanitária (medicamentos, drogas, farmacêuticos e outros); a Lei 6.437, de 20 de agosto de 1977, trata das infrações à legislação sanitária federal; Lei 6.938, de 31 de agosto de 1981, dispõe sobre a política nacional de meio ambiente. (GAIGER, 1984 apud FERRARI, Antenor. Agrotóxicos: a praga da dominação. Porto Alegre: Mercado Aberto, 1985, p.51-52). 
Em 1982, surgiu a Lei Estadual de Agrotóxicos do Rio Grande do Sul, que teve como estopim de sua criação a identificação pelo Departamento Municipal de Águas e Esgotos de Porto Alegre, de resíduos de heptacloro, endosulfan e outros nas águas do Rio Guaíba. Tais produtos da família dos organoclorados eram amplamente utilizados na produção agrícola da região.

A notícia mobilizou um conjunto de organizações ${ }^{17}$, que passou a se reunir na Comissão de Direitos Humanos da Assembleia Legislativa do Estado para discutir a questão dos agrotóxicos. As exigências iniciais, que eram de proibição da comercialização e uso, no território gaúcho dos compostos $\operatorname{organosclorados}^{18}$ e a realização de estudos sobre a problemática dos efeitos toxicológicos dos organoclorados, visto que não haviam informações consistentes sobre o assunto ${ }^{19}$, terminaram resultando, depois de um intenso embate com os defensores dos agrotóxicos, na edição da Lei $\mathrm{n}^{\mathrm{o}}$ 7.747, de 22 de dezembro de 1982. A Lei gaúcha tornou-se a primeira Lei específica sobre os agrotóxicos no país, e inspirou a criação de várias outras leis estaduais, como bem destaca Ferrari:

\begin{abstract}
As leis estaduais surgiram como resultado de um intenso processo de mobilização política iniciado no Rio Grande do Sul, no ano de 1982, e ampliado para todo o país, em 1983. A Lei Estadual 7.747/82, do Rio Grande do Sul, constituiu-se no parâmetro utilizado para a elaboração das leis estaduais de outros Estados ${ }^{20}$
\end{abstract}

Apenas em 1985, quando o então Presidente José Sarney nomeou Pedro Simon como Ministro da Agricultura, é que se tentou construir uma legislação federal específica para os agrotóxicos. O Decreto $n^{\circ}$ 91.633, de 09 de setembro de 1985, criou a Comissão Especial para propor a reformulação da legislação que dispõe sobre o comércio e o uso de agrotóxicos e biocidas. $\mathrm{O}$ art. $1^{\mathrm{o}}$ determinava que a comissão criada fícava

\footnotetext{
${ }^{17}$ N. do A. "Associação Democrática Feminina Gaúcha - ADFG; Centro de Estudos de Toxicologia do RS; Associação Gaúcha de Proteção ao Ambiente Natural - AGAPAN; Federação das Associações de Bairros do RS - FRACAB; Movimento de Justiça e Direitos Humanos; Sociedade de Agronomia; Sociedade de Engenharia; Instituto de Direito Ecológico; Fundação Balduino Rambo; Associação dos Farmacêuticos Químicos; Associação Gaúcha dos Sociólogos; Centro dos Professores do RS; Associação de Preservação da Natureza do Vale Gravataí; Institutos dos Arquitetos do Brasil e Sindicato dos Arquitetos". (FERRARI, Antenor. Agrotóxicos: a praga da dominação. Porto Alegre: Mercado Aberto, 1985, p.53)

${ }^{18}$ Com exceção do produto Dodecacloro (Mirex) para uso específico no combate à formiga cortadeira, enquanto não houvesse outro produto para substituí-lo que não fosse clorado, ou algum processo alternativo de controle. (FERRARI, Antenor. Agrotóxicos: a praga da dominação. Porto Alegre: Mercado Aberto, 1985, p.53)

${ }^{19}$ Cf. Ibidem, p.53

${ }^{20}$ Ibid., p.52.
} 
incumbida de elaborar estudos para a reformulação da legislação que dispõe sobre a fiscalização da produção, da exportação, da importação, da comercialização e da utilização dos agrotóxicos e biocidas, inclusive de seus componentes.

A Comissão Especial criada tinha 27 membros e mesmo com uma composição bastante ampla e representando interesses opostos, alguns até antagônicos, tais como os interesses das empresas de agrotóxicos e os interesses das entidades ambientalistas, conseguiu dentro do prazo estipulado construir um anteprojeto de lei para a questão dos agrotóxicos. "Em ato solene, no dia 9 de janeiro de 1986, ele foi entregue pelo professor Flavio Lewgoy, decano representante da Agapam ${ }^{21}$, ao Ministro Pedro Simon" 22 .

O Ministro enviou o anteprojeto à Casa Civil que tentou devolve-lo alegando necessidade de correções de constitucionalidade. Pedro Simon já estava para sair do cargo e diante disso não aceitou a devolução. No entanto, o novo Ministro Íris Resende, sucessor de Pedro Simon no Ministério da Agricultura, aceitou a volta do anteprojeto, e autorizou que fossem feitas alterações, mesmo sob forte manifestação contrária de ex-integrantes da comissão especial. As alterações no anteprojeto atendiam com as pressões exercidas pelos representantes da indústria de agrotóxicos. A resistência às alterações foram tantas que o anteprojeto ficaria parado no palácio por quatro anos, sem nenhuma movimentação para sua aprovação ${ }^{23}$.

Apenas em 1988, com a morte do seringueiro líder ambientalista Chico Mendes, que havia no ano anterior recebido o "Prêmio Global 500" das Nações Unidas, e o prêmio "Por Uma Vida Melhor", é que a questão dos agrotóxicos voltou à agenda legislativa.

As pressões internacionais frente a questão ambiental, em especial no que se refere a Amazônia, tomaram dimensões jamais esperadas pelo governo militar, o assassinato de Chico Mendes, tornou-se algo de relevância internacional. O constrangimento fez com que o governo, a fim de diminuir as pressões internacionais e

\footnotetext{
${ }^{21}$ Associação Gaúcha de Proteção ao Meio Ambiente - AGAPAM. Foi uma das principais organizações no processo de elaboração da Lei Estadual de Agrotóxicos do Rio Grande do Sul, e também no processo de elaboração da legislação federal. Dentre seus principais quadros estavam José Lutzenberger e Sebastião Pinheiro.

${ }^{22}$ PINHEIRO, Sebastião; NASR, Nasser Youssef; LUZ, Dioclécio. A Agricultura Ecológica e a Máfia dos Agrotóxicos no Brasil. Porto Alegre: Edição dos Autores, 1993, p. 61.

${ }^{23}$ Cf. Ibid., p. 61-62.
} 
nacionais, apresentasse um pacote de medidas de caráter ambiental chamado de "Programa Nossa Natureza" 24.

No âmbito do Programa Nossa Natureza, o anteprojeto de agrotóxicos que encontrava-se engavetado, é retomado, e em 24 de abril de 1989 ele é submetido pelo Poder Executivo ao reexame do Congresso Nacional, onde recebeu a caracterização de $\mathrm{PLn}^{\mathrm{o}}$ 1.924. Como o projeto foi enviado em regime de emergência, este teria então apenas 45 dias para sua apreciação, e caso não fosse apreciado, seria aprovado automaticamente por decurso de prazo e sancionado.

Durante o processo de tramitação o PL1.924 recebeu 28 emendas parlamentares que em geral buscavam contribuir com a redação do texto, sem alterações de conteúdo, com exceção apenas do substitutivo proposto pelo Deputado Federal Jonas Pinheiro, que propôs um novo PL que ao tramitar foi recusado por todas as comissões que o apreciou ${ }^{25}$. Nas Comissões, três foram os substitutivos propostos, como bem relata Pinheiro:

\begin{abstract}
Na Comissão de Agricultura e Política Agrária, ele recebeu um substitutivo do relator Giovani Mazzini, PMDB-PR. Na Comissão de Economia, Indústria e Comércio recebeu outro Substitutivo de autoria de Lima Cavalcânti, PDT-PE na época, que anteriormente, como Deputado estadual por Pernambuco, tinha feito cinco leis sobre meio ambiente, com minha ajuda e do Lutzenberger. Entre elas a Lei Estadual de Agrotóxicos de Pernambuco. A proposta de Lima Cavalcânti era muito boa e feita com auxílio de funcionários honestos do Ministério da Agricultura ligados ao PDT. O outro substitutivo era da Comissão de Meio Ambiente, presidida por Sandra Cavalcânti, PFL-RJ na época, e escoltada por Fábio Feldman, PSDB-SP, um jovem ambientalista de São Paulo, expoente no Congresso na defesa ambiental ${ }^{26}$.
\end{abstract}

Frente as três propostas de substitutivo, acordou-se pela construção de uma única redação, afinal havia a necessidade de se chegar a um texto comum, haja visto que o prazo para apreciação parlamentar estava por exaurir-se, o que se ocorresse sem que os parlamentares tivessem aprovado teor consensual, o projeto inicial enviado pelo Poder Executivo é que terminaria por ser sancionado. ${ }^{27}$

\footnotetext{
${ }^{24}$ Criado pelo Decreto 96.944, de 12 de outubro de 1988.

${ }^{25}$ Cf. FRANCO, Caroline da Rocha. A formulação da política de agrotóxicos no Brasil. 2014. 139 f. Dissertação (mestrado) - Setor de Ciências Sociais Aplicadas, Programa de Pós-Graduação em Políticas Públicas, Universidade Federal do Paraná, Curitiba, 2014, p. 59-60.

${ }^{26}$ PINHEIRO, Sebastião; NASR, Nasser Youssef; LUZ, Dioclécio. A Agricultura Ecológica e a Máfia dos Agrotóxicos no Brasil. Porto Alegre: Edição dos Autores, 1993, p.26-27

27 Sebastião Pinheiro conta com detalhes a elaboração do texto comum, um relato importante por seu significado histórico que vale a pena ser conferido entre as páginas 27 e 29 do livro "A Agricultura Ecológica e a Máfia dos Agrotóxicos no Brasil”.
} 
Destarte, considerando todas as apreciações feitas durante o processo de tramitação, tais como as propostas de emendas e substitutivos, chegou-se a um texto comum para o Projeto de Lei 1.924, que por sua vez foi aprovado no dia 15 de junho de 1989 pela Câmara dos Deputados e enviado ao Senado, que o apreciou em caráter revisório e o aprovou no dia 06 de julho de 1989 sem nenhuma alteração. Assim, apenas cinco dias depois, o PL 1.924, já devidamente aprovado, foi sancionado pelo Presidente José Sarney como Lei Federal n $n^{0} 7.802$, de 11 de julho de 1989, tornando-se assim, a primeira Lei de caráter amplo e específica sobre os agrotóxicos, inaugurando uma nova concepção regulamentar sobre o tema, e convertendo-se na pedra angular de todo o sistema normativo de agrotóxicos brasileiro. ${ }^{28}$

\section{O PROJETO DE LEI 3200/15 E A LEI DE AGROTÓXICOS 7.802/89}

A Lei Federal de agrotóxicos, ainda que inspirada nas Leis Estaduais, não conseguiu incorporar todos os dispositivos protetivos previstos nelas. Apenas para exemplificar, a proibição de agrotóxicos banidos em seus países de origem, tal como determina o art. $1^{\circ}$, parágrafo $2^{\circ}$, da Lei de agrotóxicos do Rio Grande do Sul, ainda que extremamente importante, não foi incorporada pela Lei Federal.

O dispositivo acima mencionado seria extremamente relevante, e atualmente é bandeira de reivindicação das organizações de luta contra os agrotóxicos, visto que no que se refere a agrotóxicos, entre produzidos e importados “[...] dos cinquenta mais utilizados nas lavouras de nosso país, 22 são proibidos na União Européia"29. Isso demonstra como o Brasil vem se tornando a maior lixeira tóxica do mundo, afinal, a proibição desses agrotóxicos em seus países de origem, na maioria dos casos, está vinculado ao fato de terem sido constatados problemas de contaminação na saúde ou meio ambiente. Afinal, “[...] não há dúvida, estamos diante de uma verdade cientificamente comprovada: os agrotóxicos fazem mal à saúde das pessoas e ao meio ambiente" ${ }^{\text {30 }}$.

No entanto, a força do agronegócio é muito grande do ponto de vista das articulações políticas e de poder econômico, não é por acaso que nos últimos anos os seus

\footnotetext{
${ }^{28}$ Cf. FRANCO, Caroline da Rocha. A formulação da politica de agrotóxicos no Brasil. 2014. 139 f. Dissertação (mestrado) - Setor de Ciências Sociais Aplicadas, Programa de Pós-Graduação em Políticas Públicas, Universidade Federal do Paraná, Curitiba, 2014, p. 65-68.

${ }^{29}$ CARNEIRO, Fernando Ferreira (Org.); AUGUSTO, Lia Giraldo da Silva; RIGOTTO, Raquel Maria et al. Dossiê ABRASCO: um alerta sobre os impactos dos agrotóxicos na saúde. Rio de Janeiro-São Paulo: EPSJV/Expressão Popular, 2015, p.53.

${ }^{30}$ Ibid., p.417.
} 
representantes tenham assento cativo nas pastas governamentais destinadas à política agrícola, especialmente membros da Confederação Nacional da Agricultura - CNA, um dos principais espaços de articulação do agronegócio brasileiro.

Diante deste contexto, no último dia 06 de outubro de 2015, foi protocolado no Congresso Nacional, pelo Deputado Federal Covatti Filho (PP/RS) o PL3200/15 que dispõe sobre a Política Nacional de Defensivos Fitossanitários e de Produtos de Controle Ambiental, seus Componentes e Afins, bem como sobre a pesquisa, a experimentação, a produção, a embalagem e rotulagem, o transporte, o armazenamento, a comercialização, a propaganda comercial, a utilização, a importação, a exportação, o destino final dos resíduos e embalagens, o registro, a classificação, o controle, a inspeção e a fiscalização de defensivos fitossanitários e de produtos de controle ambiental, seus componentes e afins, criação da Comissão Técnica Nacional de Fitossanitários - CTNFito e dá outras providências.

Este PL propõe a reformulação da Lei de Agrotóxicos, de modo que junta coisas da Lei 7.802/89 e do Decreto 4.074/02 que a regulamenta, e além disso, incorpora as propostas de outros PLs que tramitam sobre o tema no Congresso Nacional.

O conjunto de alterações propostas, infelizmente, desmonta o sistema normativos de agrotóxicos brasileiro tal como é hoje e, ao revogar a Lei de agrotóxicos (7.802/89) instituirá - caso seja aprovado - um sistema normativo extremamente flexível e permissivo, beneficiando em especial as empresas transnacionais do ramo e, colocando em risco a saúde humana, animal e ambiental, em decorrência do desmonte normativo proposto.

O PL3200/15 propõe que os agrotóxicos passem a ser chamados de "produtos defensivos fitossanitários e de controle ambiental". A disputa em torno da nomenclatura vêm de longa data, afinal, a linguagem não é neutra, pelo contrário, carrega consigo uma carga ideológica cheia de intencionalidades. O termo agrotóxicos, demonstra uma evolução histórica no sentido de evidenciar o perigo que tais substâncias oferecem.

Analisando essa evolução, os agrotóxicos no Brasil, já tiveram positivadas três terminologias: a) Produtos Fitossanitários (Lei 4.785/65, art. $2^{\circ}$ ); b) Defensivos (Decreto-Lei 917/69, art. 2º $§ 2^{\circ}$, alínea “a”) e; c) Agrotóxicos (Carta Magna de 1988, art. $220, \S 4^{\circ}$ ). Cada nomenclatura demonstra de certa forma, o grau de conhecimento e preocupação com os perigos oferecidos por tais substâncias. Não há espaço para dúvidas, que o termo agrotóxicos é o mais apropriado, visto que evidência não apenas o uso agrícola (agro), mas também a toxidade de tais venenos (tóxicos). Dizemos venenos, 
porque existe exigência da própria Agência Nacional de Vigilância Sanitária- ANVISA, que conste nos rótulos a frase "Cuidado! Veneno".

Agrotóxicos são substâncias biocidas. Na etimologia da palavra biocida encontramos, "bio" vindo do grego bios que significa "vida", e "cida" que vem do latim caedere, que por sua vez, significa "matar". Portanto, biocida nos remete a algo feito para "matar a vida". Então quando falamos de agrotóxicos, estamos falando de substâncias feitas para matar a vida, e portanto, de substâncias muito perigosas, de modo que evidenciar esse perigo é uma obrigação que remete ao direito que a sociedade tem de saber exatamente os riscos que tais substâncias oferecem.

Portanto, adotar a terminologia "produtos defensivos fitossanitários e de controle ambiental" é obviamente uma das formas utilizada para buscar diminuir o impacto negativo em relação a imagem de tais produtos. Sem dúvidas, esta é uma atitude irresponsável e movida simplesmente pelo interesse econômico, visto que tratam-se de biocidas que têm impactos nefastos sobre a saúde e o meio ambiente.

Para Machado, ao adotar na legislação vigente o termo agrotóxicos “[...] deixou-se, finalmente, o uso do termo "defensivo agrícola", que distorcia o conceito e cuja denominação fugia da linha da terminologia internacional, que é "pesticida" ou "praguicida"" 31 . Equivoca-se o autor ao dizer que o termo deixou de ser utilizado, no entanto, está coberto de razão frente ao sentido distorcido do uso do termo defensivo agrícola. Tal reflexão aplica-se em gênero e grau para a terminologia proposta pelo PL3200/15.

Por fim, apenas para reforçar, como mencionado acima, o termo consolidado na Constituição Federal de 1988, no art. 220, $\S 4^{\circ}$, é agrotóxico, de modo que a alteração proposta pela Lei $3200 / 15$, além de imprópria do ponto de vista de explicitar os perigos oferecidos por tais produtos, é doravante inconstitucional.

Ainda sobre definições conceituais, o PL3200/15 suprime dez expressões que atualmente encontram-se no $\operatorname{art.} 1^{\circ}$ do Decreto 4.074/02, sendo: controle; equipamento de proteção individual (EPI); fiscalização; inspeção; intervalo de segurança ou período de carência em relação à cultura subsequente; país de procedência; registro especial temporário (RET); venda aplicada; agrotóxicos e registro de empresa e prestador de serviço. Perceba-se que são suprimidos do artigo das definições porque são suprimidas enquanto exigência normativa, ou substituída, como é o caso do termo agrotóxicos, já

\footnotetext{
${ }^{31}$ MACHADO, Paulo Affonso Leme. Direito Ambiental Brasileiro. 11 ed. São Paulo: Malheiros Editores, 2003, p. 558.
} 
mencionado, ou do registro especial temporário - RET, que transforma-se em permissão experimental temporária - PET. Além desta, outras 14 novas definições são agregadas, tais como cultura com suporte fitossanitário insuficiente (CSFI); produto defensivo fitossanitário; produto de controle ambiental; produto genérico, entre outros.

O PL ainda propõe a criação, no âmbito do Ministério da Agricultura, Pecuária e Abastecimento - MAPA, da Comissão Técnica Nacional de Fitossanitários CTNFito, instância colegiada multidisciplinar de caráter consultivo e deliberativo, com a finalidade de apresentar pareceres técnicos conclusivos aos pedidos de avaliação de novos produtos defensivos fitossanitários, de controle ambiental, seus produtos técnicos e afins. A Comissão Técnica Nacional de Fitossanitários - CTNFito seria composta por 23 membros efetivos e respectivos suplentes, designados pelo Ministro de Estado da Agricultura, Pecuária e Abastecimento.

A distribuição destes 23 membros ficaria da seguinte forma: 3 da área de química ou de biologia, destes sendo pelo menos dois da área de química; 3 da área de produção agrícola; 3 da área de fitossanidade; 3 da área de controle ambiental; 3 da área de saúde humana e toxicologia; 1 representante do órgão de registro e fiscalização do Ministério da Agricultura, Pecuária e Abastecimento; 1 representante do Ministério do Desenvolvimento Indústria e Comércio; 1 representante do Ministério do Meio Ambiente; 1 representante do Ministério da Saúde; 1 representante do Ministério da Ciência, Tecnologia e Inovação; 1 representante de legalmente constituído de proteção à saúde do trabalhador; 1 representante de órgão legalmente constituído representativo do produtor rural (muito provavelmente este representante seria membro da CNA, visto o vínculo da Ministra com a entidade e o fato de que a CNA já vem pleiteado o cargo); 1 representante de associações legalmente constituídas de produtores de defensivos fitossanitários (diga-se representante das empresas produtoras de agrotóxicos).

Como podemos perceber com facilidade, a composição da CTNFito, privilegia a participação do setor regulado (empresas), dos setores do governo declaradamente pró-agrotóxicos, tais como o Ministério de Indústria e Comércio, e ignora completamente setores importante da sociedade, tais como as entidades ambientalistas, pioneiras na luta pela regulação dos agrotóxicos no país.

Dentre as atribuições da CTNFito, é que estão os principais problemas, afinal, altera a responsabilidade prevista no sistema normativo de agrotóxicos segundo o conhecemos. Atualmente, no que se refere ao registro de agrotóxicos, por exemplo, a responsabilidade é tripartite, ou seja, cabe ao Ministério da Agricultura - MAPA, ao 
Ministério do Meio Ambiente através do Ibama, e ao Ministério da Saúde através da Anvisa.

Como destaca Londres, "Cada órgão faz sua análise sob o enfoque da sua área de competência: o MAPA avalia a eficácia agronômica do produto, a ANVISA avalia os riscos para a saúde da população e o IBAMA avalia os riscos para o meio ambiente" 32 , de modo que se algum dos órgão der o parecer contrário à liberação do produto, este não poderá ser registrado, e em não sendo registrado, não poderá ser produzido, exportado, importado, comercializado ou utilizado no país tal como determina o art. $3^{\circ}$ da Lei $7.802 / 89$.

Com a criação da CTNFito, passa a ser atribuição desta a avalição dos pleitos de registro de novos produtos técnicos, dos respectivos produtos formulados, pré-misturas e afins, além de emitir pareceres técnicos conclusivos nos campos da agronomia, toxicologia e ecotoxicologia sobre os pedidos de aprovação de registros de produtos, bem como as medidas de segurança que deverão ser adotadas. Quanto aos aspectos de segurança à saúde e ao meio ambiente e de eficácia dos produtos, o parecer emitido pela CTNFito vincula os demais órgãos e entidades da administração, ou seja, ele é de cumprimento obrigatório.

A CTNFito deverá avaliar e emitir seu parecer conclusivo sobre os pedidos de registros de produtos técnicos novos em até 180 dias da protocolização do pleito e os seus respectivos produtos formulados em até 90 dias da aprovação do produto técnico ou sua respectiva protocolização.

Atualmente essa avaliação leva anos, devido ao pequeno quadro de pessoal técnico existente nos três órgãos responsáveis, de modo que é evidente que a proposta de reestruturação do sistema normativo de agrotóxicos objetiva dar celeridade a liberação de agrotóxicos no país, facilitando os processos de avaliação e diminuindo o grau de exigência em relação ao que é prescrito pela legislação vigente.

A CTNFito passa a ser a principal instância no que diz respeito a liberação de agrotóxicos e a estruturação do novo sistema normativo, de modo que dentre as suas diversas atribuições, encontra-se, analisar propostas de edição e alteração de atos normativos; avaliar e homologar relatório de avaliação de risco de novo produto ou de novos usos em ingrediente ativo com monografia já editada no Brasil; estabelecer as diretrizes para a avaliação agronômica, avaliação e classificação toxicológica e ambiental

${ }^{32}$ LONDRES, Flávia. Agrotóxicos no Brasil: um guia em defesa da vida. Rio de Janeiro: AS-PTA Assessoria e Serviços a Projetos em Agricultura Alternativa, 2011, p.102. 
de produtos; estabelecer as diretrizes para os procedimentos de reavaliação dos ingredientes ativos relativos aos produtos registrados no Brasil; estabelecer e publicar a monografia de cada ingrediente ativo, bem como as alterações introduzidas; manifestarse sobre os pedidos de cancelamento ou de impugnação de produtos; promover, mediante pedido ou de ofício, a reavaliação de produtos; dentre diversas outras.

Uma alteração extremamente preocupante diz respeito aos casos de proibição de registro de agrotóxicos no país. Pois de acordo com o art. $3^{\circ}, \S 6^{\circ}$ da Lei 7.802/89:

\begin{abstract}
Fica proibido o registro de agrotóxicos, seus componentes e afins: a) para os quais o Brasil não disponha de métodos para desativação de seus componentes, de modo a impedir que os seus resíduos remanescentes provoquem riscos ao meio ambiente e à saúde pública; b) para os quais não haja antídoto ou tratamento eficaz no Brasil; c) que revelem características teratogênicas, carcinogênicas ou mutagênicas, de acordo com os resultados atualizados de experiências da comunidade científica; d) que provoquem distúrbios hormonais, danos ao aparelho reprodutor, de acordo com procedimentos e experiências atualizadas na comunidade científica; e) que se revelem mais perigosos para o homem do que os testes de laboratório, com animais, tenham podido demonstrar, segundo critérios técnicos e científicos atualizados; f) cujas características causem danos ao meio ambiente ${ }^{33}$.
\end{abstract}

Entretanto, o PL 3200/15, propõe de forma sutil, significativas alterações

em relação a estes casos. Dispõe o PL no art. 20, que:

\begin{abstract}
Fica proibido o registro de produto defensivo fitossanitário, de controle ambiental, seus componentes e afins: a) para os quais o Brasil não disponha de métodos para desativação de seus componentes, de modo a impedir que os seus resíduos remanescentes provoquem riscos inaceitáveis ao meio ambiente e à saúde pública; b) para os quais não haja antídoto ou tratamento eficaz no Brasil; de acordo com os conhecimentos técnicos e científicos atuais; c) que revelem um risco inaceitável para características teratogênicas, carcinogênicas ou mutagênicas, de acordo com os resultados atualizados de experiências da comunidade científica; d) que revelem um risco inaceitável para distúrbios hormonais, danos ao aparelho reprodutor, de acordo com procedimentos e experiências atualizadas na comunidade científica; e) que revelem um risco inaceitável mais perigoso para o homem do que os testes de laboratório, realizados com animais ou através de métodos alternativos, tenham podido demonstrar, segundo critérios técnicos e científicos atualizados; f) cujas características revelem um risco inaceitável para saúde humana, meio ambiente e agricultura, segundo critérios técnicos e científicos atualizados ${ }^{34}$.
\end{abstract}

Não é preciso uma grande avaliação técnica, nem tampouco uma análise hermenêutica complexa, para perceber que o texto proposto pelo PL3200/15, deixa claro

\footnotetext{
${ }^{33}$ BRASIL. Lei no 7.802, de 11 de julho de 1989. Diário Oficial [da República Federativa do Brasil], 1989, art. $3^{\circ}, \S 6^{\circ}$.

${ }^{34}$ BRASIL. Câmara dos Deputados. Projeto de Lei PL 3200, de 06 de outubro de 2015, art. 20 (Grifo nosso).
} 
que passa-se a admitir determinados "riscos aceitáveis", visto que o texto menciona a existência de "riscos inaceitáveis". Não se trata de um jogo de palavras, trata-se de tornar o sistema normativo de agrotóxicos permissivo no que se refere às características teratogênicas, carcinogênicas e, mutagênicas dos produtos, bem como os seus efeitos referentes à distúrbios hormonais, danos ao aparelho reprodutor, e aos perigos e riscos que tais substâncias oferecem a saúde humana, ao meio ambiente e a agricultura em seu conjunto.

Estamos portanto tratando, de um conjunto de violações de direitos conquistados historicamente, tais como o direito a saúde, ao meio ambiente equilibrado, dentre outros. O que vemos são propostas que apontam para a violação de direitos de segunda e de terceira geração, e ao tratar dos direitos de terceira geração, ainda que, segundo Bobbio, trata-se de uma categoria excessivamente heterogênea e vaga, o renomado autor afirma que "[...] o mais importante deles é o reivindicado pelos movimentos ecológicos: o direito de viver num ambiente não poluído" ${ }^{35}$. As propostas do art. 20 do PL3200/15, vão de encontro a estes direitos.

Ao tratar das competências, da União, dos Estados, do Distrito Federal e dos Municípios, que constam no art. $9^{\circ}$ da Lei 7.802/89, o PL3200/15, é suprimido o mecanismo normativo que permitia os Estados e o DF legislar sobre a produção, bem como fiscalizar o consumo e o comércio de tais produtos. Aos Estados, o DF e os Municípios é vedada explicitamente a possibilidade de restringir o alcance do registro federal, a menos que seja para atender uma particularidade regional ou local devidamente justificada. No entanto, não aponta como seria ou quem reconheceria essa justificativa, o que muito possivelmente aponta para a ocorrência de demandas jurídicas sobre a questão, visto que hoje, quando tratamos de competência, mesmo sendo a Lei 7.802/89 e o Decreto 4.074/02 bastante claros, existem diversas ações tramitando para discutir competência. Em geral são ações propostas pelas empresas contra as leis estaduais de agrotóxicos.

Ainda, segundo o PL3200/15, passa a ser facultativo a devolução das embalagens vazias de agrotóxicos, excluindo assim do ordenamento jurídico, o que determina a o art. $6^{\circ}, \S 2^{\circ}$ da Lei 7.802/89. Hoje, mesmo com a exigência da devolução, é recorrente problemas advindos do descarte das embalagens no meio ambiente, imaginese então, sem nenhuma exigência normativa, tornar-se-á o meio ambiente o principal algo do descarte ora irregular.

\footnotetext{
${ }^{35}$ BOBBIO, Norberto. A era dos direitos. Rio de Janeiro: Elsevier, 2004, p.5.
} 


\section{CONCLUSÃO}

Várias outras alterações ainda são propostas pelo PL3200/15, porém, não é necessário que sigamos a expor detalhadamente as sugestões de alterações, visto que com o exposto até aqui, já é possível perceber que a revogação proposta da Lei 7.802/89, representa o desmonte do sistema normativo de agrotóxicos atual, e a consolidação de um novo sistema estruturado sobre bases extremamente permissivas e submissas aos interesses das empresas produtores de agrotóxicos e do agronegócio.

A construção do atual sistema normativo de agrotóxicos foi árdua, muitas foram as lutas para que chegássemos a uma estrutura normativa mais protetiva da saúde humana e do ambiente, todavia ainda existem questões para avançar, tais como o banimento dos agrotóxicos já proibidos em seus países de origem; a proibição da pulverização aérea que tem como deriva técnica $70 \%$ daquilo que é pulverizado, não atingindo o alvo, mas contaminando a água e a terra; o fim das isenções fiscais que isentam as empresas, de modo que elas causam um conjunto de contaminações e problemas sociais, mas ficam com o lucro sem arcar com responsabilidades tributárias, etc.

O problema dos agrotóxicos e a questão dos direitos violados pelo simples uso destas substâncias é uma demanda contemporânea, que precisa inclusive, do ponto de vista da doutrina jurídica, contar com pessoas que possam se debruçar sobre o tema a fim de construir com a participação da sociedade, propostas que possam qualificar o sistema normativo de agrotóxicos, e não desmontá-lo como propõe o PL3200/15. Enfrentar tais questões atualíssimas é uma exigência histórica de nosso tempo, e nossa postura agora será alvo de cobrança das futuras gerações e do próprio planeta. Afinal, como bem questiona Rachel Carson, em seu clássico Primavera Silenciosa "Como é possível que seres inteligentes tenham almejado controlar umas poucas espécies indesejadas por um método que contaminou todo o meio ambiente e trouxe a ameaça da doença e da morte inclusive para sua própria espécie?"36.

\footnotetext{
${ }^{36}$ CARSON, Rachel. Primavera Silenciosa. Tradução de Claudia Sant'Anna Martins. São Paulo: Gaia, 2010, p.24-25.
} 


\title{
SISTEMA REGULADOR DE PLAGUICIDAS EN CONTEMPORÁNEO
}

\author{
Cleber Adriano Rodrigues Folgado
}

\section{RESUMÉN}

Desde 2008, Brasil es el mayor consumidor de pesticidas del mundo, a pesar de la utilización masiva de este tipo de productos en la agricultura brasileña viene desde los años 1960. La regulación del uso de dichas sustancias ha durado en nivel federal sin una regla específica hasta la promulgación de la Ley 7.802, de 11 de julio de 1989, más conocida como "Ley de Agrotóxicos". Ya en su principio, la ley provocó fuertes debates y confrontaciones, sin embargo, recientemente se ha presentado en la Cámara de los Diputados, el Proyecto de Ley 3200/15, que cambia completamente la estructura del sistema de regulación de pesticidas y propone la derogación de la Ley 7.802/89. Las modificaciones propuestas representan el desmantelamiento de varios logros - resultado de las luchas históricas del pueblo brasileño - positivadas en nuestro sistema jurídico en lo tocante a los pesticidas. Este artículo tiene como objetivo exponer sobre este proceso $\mathrm{y}$, por lo tanto, sobre violaciones de los derechos relacionados con el tema.

Palabras clave: Revolución Verde. Agronegócios. Ley de Plaguicidas. Proyecto de Ley.

\section{REFERÊNCIAS}

BOBBIO, Norberto. A era dos direitos. Rio de Janeiro: Elsevier, 2004.

BRASIL. Constituição da Republica Federativa do Brasil de 1988. Diário Oficial [da República Federativa do Brasil], 1988. Brasília, Brasil. Disponível em: $<$ http://www.planalto.gov.br/ccivil_03/constituicao/constituicao.htm>. Acesso em: $11 / 01 / 2015$.

BRASIL. Decreto $n^{\circ} 96.944$, de 12 de outubro de 1988. Cria o Programa Nossa Natureza. Diário Oficial [da República Federativa do Brasil], 1988. Brasília, Brasil. Disponível em: $<$ http://www.planalto.gov.br/ccivil_03/decreto/1980-1989/D96944.htm>. Acesso em: 03 fev. 2016.

BRASIL. Lei $n^{\circ}$ 7.802, de 11 de julho de 1989. Diário Oficial [da República Federativa do Brasil], 1989. Lei, Brasília, Brasil. Disponível em: $<$ http://www2.camara.leg.br/legin/fed/lei/1989/lei-7802-11-julho-1989-356807normaatualizada-pl.pdf> . Acesso em: 29 jan. 2016.

BRASIL. Decreto $n^{\circ}$ 4.074, de 04 de janeiro de 2002. Diário Oficial [da República Federativa do Brasil], 2002. Brasília, Brasil. Disponível em: <http:// https://www.planalto.gov.br/ccivil_03/decreto/2002/d4074.htm $>$. Acesso em: 03/02/2016. 
BRASIL. Câmara dos Deputados. Projeto de Lei PL 3200, de 06 de outubro de 2015. Dispõe sobre a Política Nacional de Defensivos Fitossanitários e de Produtos de Controle Ambiental, seus Componentes e Afins, bem como sobre a pesquisa, a experimentação, a produção, a embalagem e rotulagem, o transporte, o armazenamento, a comercialização, a propaganda comercial, a utilização, a importação, a exportação, o destino final dos resíduos e embalagens, o registro, a classificação, o controle, a inspeção e a fisscalização de defensivos fitossanitários e de produtos de controle ambiental, seus componentes e afins, e dá outras providências. Disponível em: $<$ http://www2.camara.leg.br/proposicoesWeb/prop_mostrarintegra;jsessionid=100A962 40E8E0740692BF8516C3F37DF.proposicoesWeb2 ?codteor $=1412079 \&$ filename $=$ PL + 3200/2015. Acesso em: 03 de fev. 2016.

CARSON, Rachel. Primavera Silenciosa. Tradução de Claudia Sant'Anna Martins. São Paulo: Gaia, 2010.

CARNEIRO, Fernando Ferreira (Org.); AUGUSTO, Lia Giraldo da Silva; RIGOTTO, Raquel Maria et al. Dossiê ABRASCO: um alerta sobre os impactos dos agrotóxicos na saúde. Rio de Janeiro-São Paulo: EPSJV/Expressão Popular, 2015.

FELIPE, Donaldo J. Dicionário jurídico de bolso: terminologia jurídica - termos e expressões latinas de uso forense. 15 ed. Campinas: Millennium, 2002.

FERRARI, Antenor. Agrotóxicos: a praga da dominação. Porto Alegre: Mercado Aberto, 1985.

FRANCO, Caroline da Rocha. A formulação da política de agrotóxicos no Brasil. 2014. 139 f. Dissertação (mestrado) - Setor de Ciências Sociais Aplicadas, Programa de PósGraduação em Políticas Públicas, Universidade Federal do Paraná, Curitiba, 2014.

LONDRES, Flávia. Agrotóxicos no Brasil: um guia em defesa da vida. Rio de Janeiro: AS-PTA - Assessoria e Serviços a Projetos em Agricultura Alternativa, 2011.

MACHADO, Paulo Affonso Leme. Direito Ambiental Brasileiro. 11 ed. São Paulo: Malheiros Editores, 2003.

PEREIRA, Mônica Cox de Britto. Revolução Verde. In: CALDART, Roseli Salete (Org.); PEREIRA, Isabel Brasil; ALENTEJANO, Paulo et al. Dicionário de Educação do Campo. Rio de Janeiro-São Paulo: Escola Politécnica de Saúde Joaquim Venâncio/Expressão Popular, 2012.

PINHEIRO, Sebastião; NASR, Nasser Youssef; LUZ, Dioclécio. A Agricultura Ecológica e a Máfia dos Agrotóxicos no Brasil. Porto Alegre: Edição dos Autores, 1993.

RIGOTTO, Raquel Maria; ROSA, Islene Ferreira. Agrotóxicos. In: CALDART, Roseli Salete (Org.); PEREIRA, Isabel Brasil; ALENTEJANO, Paulo et al. Dicionário de Educação do Campo. Rio de Janeiro-São Paulo: Escola Politécnica de Saúde Joaquim Venâncio/Expressão Popular, 2012.

RIO GRANDE DO SUL. Lei Estadual $n^{\circ}$ 7.747, de 22 de dezembro de 1982. Dispõe sobre o controle de agrotóxicos e outros biocidas a nível estadual e dá outras providências. Diário Oficial [do] Estado do Rio Grande do Sul, 1982. Porto Alegre, RS. Disponível em: 
$<$ http://www.al.rs.gov.br/filerepository/repLegis/arquivos/07.747.pdf $>$. Acesso em: 03 fev. 2016.

SILVA JUNIOR, Décio Ferraz. Legislações Estaduais: agrotóxicos e afins. São Paulo: Akai Comunicação, 2006.

SILVA JUNIOR, Décio Ferraz. Legislações Federal: agrotóxicos e afins. Piracicaba: FEALQ, 2008. 